\title{
Intracranial Chondrosarcoma
}

\section{-Case Report-}

\author{
Tadao MiYAMORI, Hidetaka MizuKosHI, Kiyotoshi YAMANO, \\ Nobutatsu TAKAYANAGI*, Minoru SUGINO**, Hideo HAYASE*** \\ and Haruhide $\mathrm{ITO}^{* * * *}$
}

\begin{abstract}
Department of Neurosurgery and ${ }^{*}$ Central Laboratory, Toyama Municipal Hospital, Toyama; ${ }^{* *}$ Sugino Neurosurgical Hospital, Toyama; ***Department of Neurosurgery, School of Medicine, Kanazawa University, Kanazawa; ${ }^{* * *}$ Department of Neurosurgery, Yamaguchi University School of Medicine, Ube, Yamaguchi
\end{abstract}

\begin{abstract}
The authors report the case of a 54-year-old male who was found to have a large intracranial chondrosarcoma at the site from which chondromas had been partially removed twice, 6 and 10 years previously. On the third admission, the second through tenth and the twelfth cranial nerves on the right side were involved. Computed tomographic scans showed a large mass in the right middle and posterior fossae and the right ethmoid sinus. Angiography demonstrated an extradural mass in the right middle fossa. The tumor in the middle and posterior fossae was subtotally removed, and second, third, and eighth cranial nerve function improved postoperatively. Histological examination of tumor specimens showed active proliferation of poorly differentiated cartilagenous cells, suggestive of sarcomatous transformation of the pre-existing chondroma. It is emphasized that chondromas should be removed as completely as possible and that patients must be followed carefully after surgery.
\end{abstract}

Key words: chondroma, chondrosarcoma, brain neoplasms, tumor removal, tumor recurrence

\section{Introduction}

Intracranial chondromas are very rare, constituting only $0.1-0.2 \%$ of all intracranial tumors. ${ }^{16,19)}$ These tumors tend to grow slowly, and the prognosis is widely regarded as favorable. We recently encountered a patient who had undergone neurosurgery twice before, both times with a diagnosis of chondroma. At the third surgery, the tumor was found to cover the right middle and posterior cranial fossae and the paranasal sinuses. This tumor was histologically diagnosed as a chondrosarcoma.

\section{Case Report}

The patient was first admitted to a hospital in 1977, at which time an extradural tumor diagnosed as a chondroma was only partially removed from the

\section{Received November 17, 1987; Accepted May 22,} 1989 right middle cranial fossa. On his second admission to the same institution in December of 1980, a precontrast computed tomographic (CT) scan revealed that the tumor had extended into the sella turcica and sphenoid sinus (Fig. 1). The histological diagnosis of the tumor, which was again partially removed from the right middle fossa, was also chondroma.

When he was admitted to our hospital, in November of 1986, he was 54 years old and had suffered severe occipitalgia for the previous month. His signs and symptoms on this admission were confined to the right side and indicated involvement of the second through tenth, as well as the twelfth, cranial nerves. Right visual symptoms included amaurosis, blepharoptosis, impaired eyeball movement (abduction, supraduction, and infraduction were impossible), anisocoria, and absence of direct light reflex. Also on the right side, he exhibited anesthesia or hypesthesia in the region of rami 1 through 3 of the trigeminal nerve, peripheral facial 


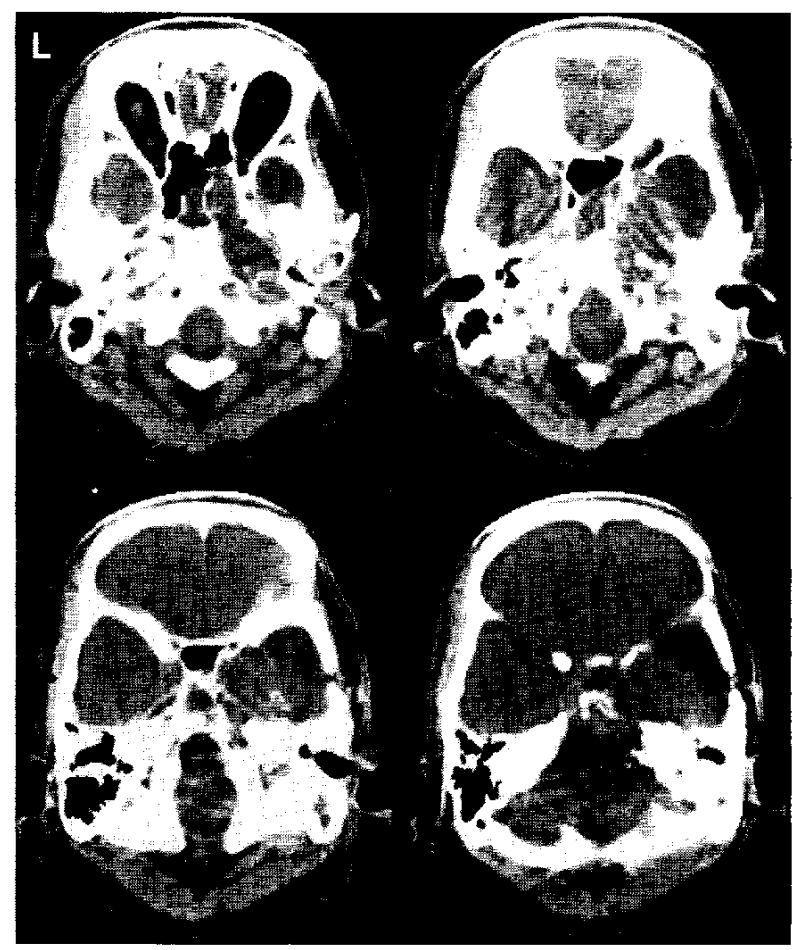

Fig. 1 Preoperative precontrast CT scans obtained in 1980, showing a tumor in the right middle fossa, sella turcica, and sphenoid sinus.

paresis, impaired gustation, mixed hearing difficulty, and absence of the deglutition reflex. Additional symptoms were hoarseness and deviation of the tongue toward the right. Tomography of the skull demonstrated a thin base and partial destruction of the right middle fossa, evidence of tumor in the paranasal sinus, and destruction of the clivus. CT scans showed partial calcification and contrast enhancement of the tumor. The tumor was predominantly located in the right middle cranial fossa and had invaded the posterior cranial fossa and the upper sella turcica (Fig. 2 upper, middle). A coronal section showed that the large tumor in the right middle cranial fossa extended to the ethmoid sinuses and the upper sella turcica (Fig. 2 lower). Right carotid angiography demonstrated elevation of the carotid siphon and constriction and elongation of the intraosseous portion of the internal carotid artery. The tumor was not visualized (Fig. 3). Retrograde brachial angiography showed posterior deviation of the basilar artery due to compression.

Through a right frontotemporal craniotomy, a very large extradural tumor was found after ablation of the dura from the cranial base to the cortex. The dura was incised, and the hemorrhagic, jelly-like tumor, which overlay the middle and posterior cranial fossae, was removed to the extent possible. The pyramis had been destroyed. The portion of the tumor that had invaded the cavernous sinus was not removed.

Postoperative CT scans showed that the portion of the tumor in the middle cranial fossa had been almost completely removed, and the portion in the posterior cranial fossa had been reduced in volume (Fig. 4). The right blepharoptosis improved, and the right visual field expanded inferiorly. Right hearing also improved in terms of high-pitched
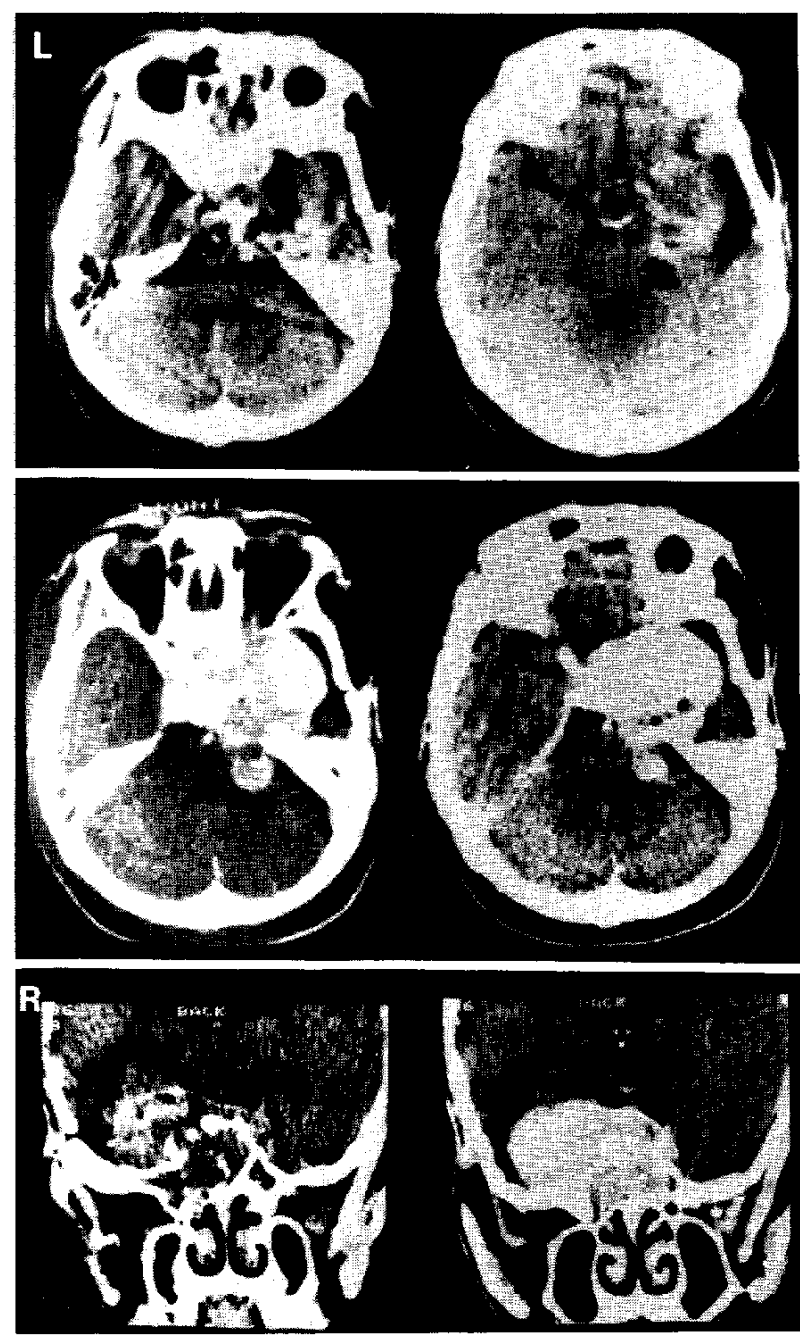

Fig. 2 Preoperative axial and coronal CT scans. upper: Precontrast images show calcification within the tumor. middle: Postcontrast scans, showing the extent of the tumor. lower: Postcontrast coronal CT scans, revealing tumor in the ethmoid sinus and the suprasellar region. 


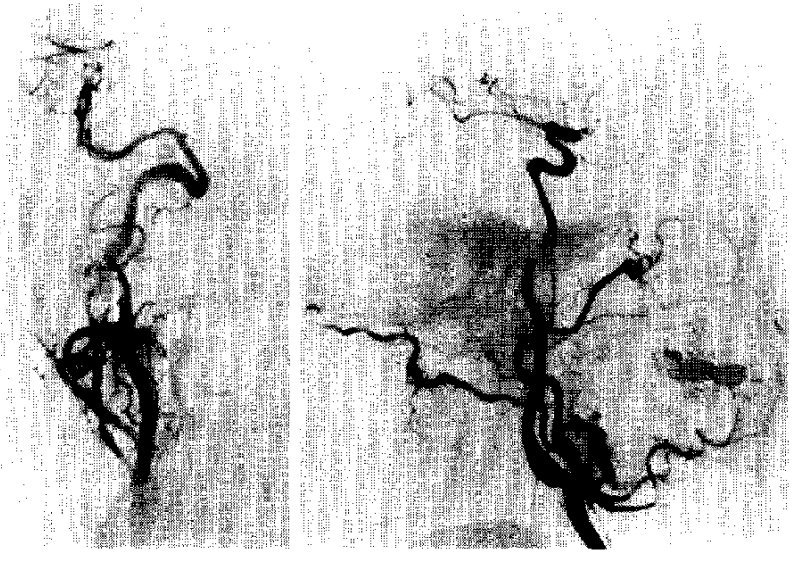

Fig. 3 Carotid angiograms. left: Anteroposterior view, showing elevation of the $\mathbf{M}_{1}$ segment of the middle cerebral artery. right: Lateral view, demonstrating elevation of the carotid siphon and stretching of the intraosseous portion of the internal carotid artery.

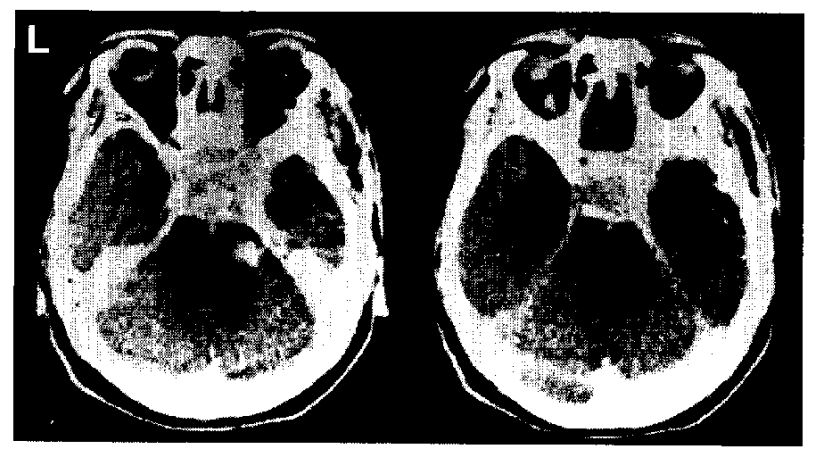

Fig. 4 Postoperative CT scans, which indicate that the tumor has been largely removed; residual tumor is seen in the vicinity of the cavernous sinus. tones.

In tumor specimens obtained at the first operation, in 1977, the main histological finding was proliferative, cartilaginous tumor cells in an abundant matrix (Fig. 5 left). The tumor specimens taken in 1980 exhibited essentially the same features as those of the earlier specimens, except that the tumor cells were denser (Fig. 5 right). The tumor obtained at the third surgery consisted primarily of dense, poorly differentiated cells and contained less matrix. At high magnification, tumor cells showed a high proportion of nuclear $v s$, protoplasmic material, a richness of nuclear chromatin, and variability in the size of nuclei. Some cells contained two nuclei, and there were many mitoses (Fig. 6). The tumor was diagnosed as a chondrosarcoma.

As of March of 1990, he is alive, but the impairments of the cranial nerves are still persisted.

\section{Discussion}

There are five types of cartilaginous tumors: osteochondroma, chondroma, chondromyxoid fibroma, benign chondroblastoma, and chondrosarcoma. ${ }^{28)}$ Chondroma and osteochondroma are the commonest; in a series of 113 cases, Berkmen and Blatt ${ }^{5}$ found that $94(83 \%)$ were diagnosed as chondroma or osteochondroma.

Many intracranial chondromas occur near the foramen lacerum ${ }^{10,16,27)}$ where cartilage connections, such as the synchondrosis sphenopetrosa, petrooccipitalis, and sphenooccipitalis are clustered. ${ }^{24,27)}$ Since chondromas rarely develop at fibrous connections of the convexity, the hypothesis that they arise from residual chondrocytes, proposed by List, ${ }^{18)}$ is credible.

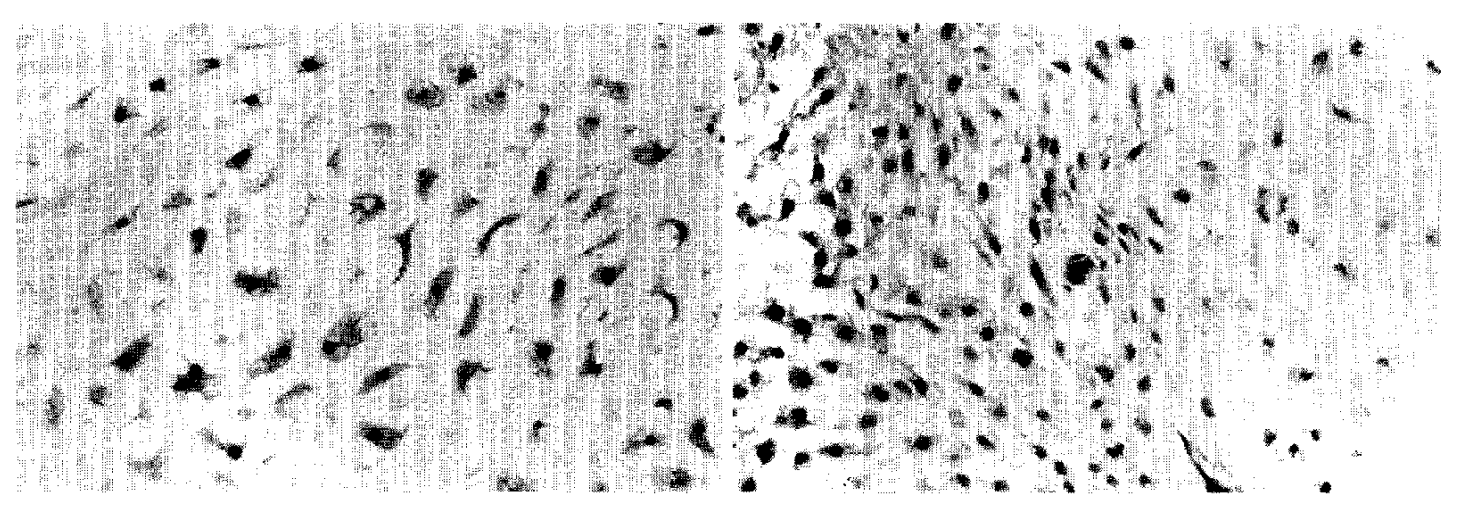

Fig. 5 Photomicrographs of earlier tumor specimens. left: The tumor removed in 1977 consists of mature chondroma cells in an ample matrix. right: Somewhat proliferative, immature tumor cells are observed in the specimen taken in 1980. HE stain, $\times 200$. 

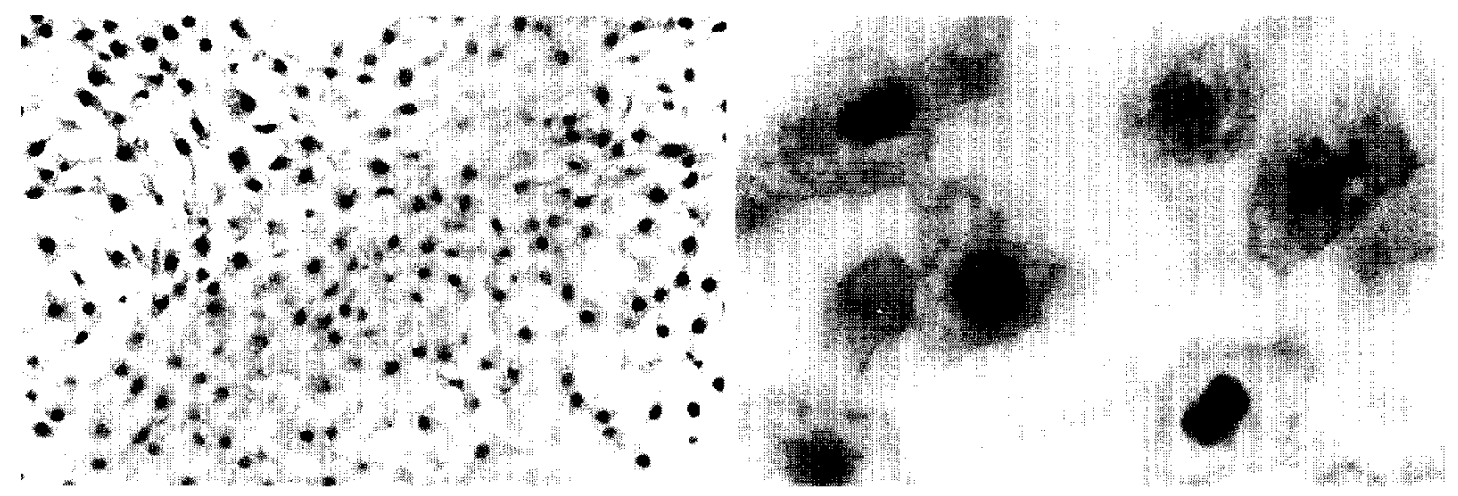

Fig. 6 Photomicrographs of the tumor obtained at the third operation (1986), showing marked proliferation of poorly differentiated tumor cells (left) and, on higher magnification, mitotic figures (right). HE stain, $\times 200($ left $), \times 1000($ right $)$.

The commonest symptoms of chondroma are progressive ipsilateral impairment of multiple cranial nerve functions ${ }^{11)}$ and contralateral hemiparesis. ${ }^{29)}$ Bilateral cranial nerve involvement is unlikely even in the event that the tumor becomes very large, as occurred in our case. The patient's tumor occupied the right middle and posterior cranial fossae and the upper sella turcica. However, neurological impairment was confined to the second through tenth and twelfth cranial nerves on the right, and the contralateral cranial nerves were unaffected. The tumor removal alleviated impairment of the second and the third cranial nerves and the cochlear nerve.

Cranial tomograms of chondromas frequently show calcification and bony destruction ${ }^{10,16,21,23,24)}$ and, in our case, demonstrated a thin, partially destroyed middle fossa, tumor invasion of the paranasal cavity, and destruction of the clivus. Characteristic CT findings include a region of high density, corresponding to calcification, ${ }^{3,13)}$ no peripheral cerebral edema, and lack of contrast enhancement. ${ }^{6,9)}$ On the other hand, benign chondroblastoma, chondrosarcoma, and chondromyxoid fibroma are enhanced by contrast agents..$^{13,14,19,20)} \mathrm{CT}$ scans revealed his tumor to be partially calcified and highly enhanced. It has been reported that it is difficult to determine the extent of damage on the basis of $\mathrm{CT}$ findings ${ }^{19)}$ but that $\mathrm{CT}$ is useful in demonstrating tumor invasion of the paranasal cavity $\mathrm{y}^{6)}$; and in our case, CT clearly showed invasion of into the ethmoid sinuses, which enabled us to accurately estimate the extent of the tumor. Magnetic resonance imaging is also useful in detecting the presence and extent of bony invasion. ${ }^{25}$

Concerning treatment of chondroma, it has been noted that surgery is effective but that radiation therapy is not. ${ }^{10,15,23)}$ Given the slow progression of these tumors, partial removal is often preferable. ${ }^{4,29}$ ) Although some cases of total removal of chondromas at the convexity have been described, ${ }^{1,7,8,22)}$ it is difficult to achieve this if the chondroma is located at the base of the skull. ${ }^{4,11,12,23)}$ The fact that chondromas are histologically benign does not mean that the long-term prognosis is always favorable. The outcome depends on the extent of destruction, whether or not there is tumor recurrence, and the site of the tumor(s). ${ }^{17,26)}$

Alpers $^{2)}$ described a case in which an osteochondroma in the left parietal region was diagnosed as chondrosarcoma 4 years later. In our case it appeared that, at some time during this patient's 10 years of follow-up, the tumor's proliferative capacity increased and the cells became less differentiated. Thus, in cases of chondroma it is desirable to remove the tumor as completely as possible, ${ }^{25)}$ and careful, long-term follow-up is essential.

\section{Acknowledgment}

A summary of this report was presented at the 20th Meeting of the Japan Neurosurgical Society of the Chubu area, held in March, 1987 in Aichi.

\section{References}

1) Acamposa S, Troisi F, Fusco G, Del Gaizo S: Voluminous intracranial chondroma. Surg Neurol 18: 254-257, 1982

2) Alpers BJ: Cerebral osteochondroma of dural origin. Ann Surg 101: 27-37, 1935

3) Bahr AL, Gayler BW: Cranial chondrosarcomas. Radiology 124: 151-156, 1977 
4) Bakdash H, Alksne JF, Rand RW: Osteochondroma of the base of the skull causing an isolated oculomotor nerve paralysis. J Neurosurg 31: 230-233, 1969

5) Berkmen YM, Blatt ES: Cranial and intracranial cartilagenous tumours. Clin Radiol 19: 327-333, 1968

6) Downey E, Friedman AC, Finizis J: CT of nasal chondrosarcoma. $A J N R$ 3: 80-81, 1982

7) Dutton J: Intracranial solitary chondroma. $J$ Neurosurg 49: 460-463, 1978

8) Dutton J: Intracranial solitary chondroma. Acta Neurochir (Wien) 28: 442-444, 1979

9) Himuro H, Suzuki H, Takeyama E, Jinbo M, Kitamura K: A case of intracranial osteochondroma. No Shinkei Geka 5: 1079-1083, 1977 (in Japanese)

10) Ikeda $Y$, Shimura $T$, Higuchi $H$, Nakazawa $S$, Sugisaki Y: Intracranial osteochondroma. Case report. No Shinkei Geka 8: 263-269, 1980 (in Japanese)

11) Imagawa $K$, Hayashi $M$, Toda I, Asai A, Nomura T: Intracranial chondroma. Surg Neurol 8: 268-272, 1977

12) Imagawa $K$, Toda I, Hayashi $M$, Asai $A$, Nomura $T$ : A case of enchondroma of the skull base. A manifestation of generalized chondromatosis. No Shinkei Geka 5: 457-463, 1977 (in Japanese)

13) Israeli SM, Shalit MN, Cohen ML: Computed tomography in intracranial supratentorial osteochondroma. J Comput Assist Tomogr 5: 109-115, 1981

14) Kanemaru $R$, Gondo $M$, Hirahara $K$, Hamada $H$, Mihara T, Asakura T: A giant chondromyxoid fibroma originated from the right orbital roof. A case report. No Shinkei Geka 10: 731-736, 1982 (in Japanese)

15) Karino T, Nukui H, Aiba T, Kawabuchi J: A case of osteochondroma of the base of the skull. No To Shinkei 21: 699-704, 1969 (in Japanese)

16) Kikuchi K, Kowada T, Monma F, Rikimaru S, Tamagawa Y: An operated case of clivus chondroma. No Shinkei Geka 7: 271-276, 1979 (in Japanese)

17) Klingler M: Uber Knorpelgeschwulste der Schadelbasis mit intracranieller Ausdehnung. Acta Neurochir (Wien) 1: 337-380, 1951

18) List CF: Osteochondroma arising from the base of the skull. Surg Gynec Obstet 76: 480-492, 1943

19) Matsumoto N, Fukushima T, Tomonaga M,
Imamura M: Maffucci's syndrome with intracranial manifestation and chromosome abnormalities. A case report. No Shinkei Geka 14: 403-410, 1986 (in Japanese)

20) Miyake H, Hashi K, Nin K, Shimotake K, Kobayashi A, Handa Y, Hamada Y, Abe K, Miyagawa H: Intracranial benign chondroblastoma. A case report and review of the literature. No Shinkei Geka 12: 419-425, 1984 (in Japanese)

21) Nakao S, Takaoka Y, Watanabe M: A huge osteochondroma of the base of the skull with repeated subarachnoid hemorrhage. No Shinkei Geka 1: 251257, 1973 (in Japanese)

22) Ozgen T, Pamir N, Akalan N, Bertan V, Onol B: Intracranial solitary chondroma. $J$ Neurosurg 61: 399-401, 1984

23) Saito I, Nagai $M$, Tsuchida $T$, Sano K: Intracranial and calvarial chondromas. No To Shinkei 20: 10531060, 1968 (in Japanese)

24) Sakata K, Murase T, Yamada T, Ueda S, Taketomo T, Takai S: Intracranial chondroma. Report of a case and review of the literature. No To Shinkei 20: 10451052, 1968 (in Japanese)

25) Sen CN, Sekhar LN, Schramm VL, Janecka IP: Chordoma and chondrosarcoma of the cranial base: An eight-year experience. Neurosurgery 25: 931-941, 1989

26) Seth HN, Singh M: Intracranial mesenchymal chondrosarcoma. Acta Neuropathol (Berl) 24: 86-89, 1973

27) Takahashi A, Usui T, Hirota $T$, Sato O, Iwata K, Ito $\mathrm{G}$ : Solitary chondroma of the skull base. Report of an autopsied case with Garcin's syndrome and review of the literature. No To Shinkei 23: 381-390, 1971 (in Japanese)

28) Unni KK: Classification of bone tumours. Can J Surg 20: 504-509, 1977

29) Yamaguchi $T$, Wada S, Matsukado $Y$ : Intracranial giant osteochondroma with unusual clinical features. No Shinkei Geka 11: 181-184, 1983 (in Japanese)

Address reprint requests to: T. Miyamori, M.D., Department of Neurosurgery, Toyama Municipal Hospital, 292 Imaizumi, Toyama 939, Japan. 